\title{
The essential role of $\mathrm{CAMP} / \mathrm{Ca}^{2+}$ signalling in mammalian circadian timekeeping
}

\author{
John S. O'Neill ${ }^{1}$ and Akhilesh B. Reddy \\ Department of Clinical Neurosciences, University of Cambridge Metabolic Research Laboratories, \\ Institute of Metabolic Science, University of Cambridge, Addenbrooke's Hospital, Cambridge CB2 \\ OQQ, U.K.
}

\begin{abstract}
Approximately daily, or circadian, rhythms are ubiquitous across eukaryotes. They are manifest in the temporal co-ordination of metabolism, physiology and behaviour, thereby allowing organisms to anticipate and synchronize with daily environmental cycles. Although cellular rhythms are selfsustained and cell-intrinsic, in mammals, the master regulator of timekeeping is localized within the hypothalamic SCN (suprachiasmatic nucleus). Molecular models for mammalian circadian rhythms have focused largely on transcriptional-translational feedback loops, but recent data have revealed essential contributions by intracellular signalling mechanisms. cAMP and $\mathrm{Ca}^{2+}$ signalling are not only regulated by the cellular clock, but also contribute directly to the timekeeping mechanism, in that appropriate manipulations determine the canonical pacemaker properties of amplitude, phase and period. It is proposed that daily auto-amplification of second messenger activity, through paracrine neuropeptidergic coupling, is necessary and sufficient to account for the increased amplitude, accuracy and robustness of SCN timekeeping.
\end{abstract}

\section{Keywords}

calcium; cAMP; circadian rhythm; clock; second messenger; suprachiasmatic nucleus (SCN)

\section{Circadian rhythms in vivo and in vitro}

Circadian rhythms are biological oscillations with periods of approximately 1 day. They are manifest in the temporal organization of behavioural, physiological, cellular and neuronal processes, influencing phenomena as diverse as sleep/wake cycles, glucose homoeostasis, innate immunity and cell division. Because this endogenous timekeeper interacts with myriad biological systems, circadian disruption has significant effects on human health, e.g. whereas acute clock disruption results in jetlag, long-term shift workers exhibit increased susceptibility to diseased states such as Type 2 diabetes and various cancers [1]. As such, there is clear translational potential in elucidating the mechanistic basis for circadian timekeeping.

The SCN (suprachiasmatic nucleus) of the hypothalamus was long thought to be the centre of mammalian timekeeping, since its surgical ablation in rodents abolishes circadian rhythms in behaviour, body temperature and the secretion of endocrine factors such as melatonin and cortisol [2]. More recently, however, it has become apparent that circadian rhythms are a property inherent to mammalian cells, being observed to persist throughout

(C)The Authors Journal compilation@2012 Biochemical Society

${ }^{1}$ To whom correspondence should be addressed (jso22@medschl.cam.ac.uk).. 
the body in vivo, and in isolated tissues/cells for many days in vitro [3,4]. Some 10-20\% of all mammalian genes are expressed rhythmically in one or more tissues, although specific CCGs (clock-controlled genes) vary between tissues, appropriately to organ function [5-7]. Such advances have led to the widespread application of real-time bioluminescent reporters for circadian gene expression, whereby firefly luciferase fusions with relevant genomic sequences enable non-invasive long-term recordings of rhythmic bioluminescence to be made [8]. Henceforth, descriptions of SCN rhythms refer to such bioluminescence recordings, unless stated otherwise.

\section{The state of the art}

Largely on the basis of forward and reverse genetics, recent models of cellular timekeeping have focused on transcriptional-translational feedback mechanisms whereby positive activators (e.g. BMAL1 and CLOCK) rhythmically bind to commonly occurring regulatory promoter elements (e.g. E-boxes) of many CCGs, including those upstream of transcriptional 'clock gene' repressors (e.g. PERIOD1/2 and CRYPTOCHROME1/2), facilitating transcriptional activation around anticipated dawn (circadian time, CT0). The repressor proteins are processed post-translationally, eventually accumulating to form complexes later in the day, before nuclear entry around anticipated dusk (CT12). At night, these repressive complexes inhibit CLOCK/BMAL1-driven transcription in many CCG promoters, including their own, and are then progressively degraded. This licenses a relaxation from repression before dawn, when the cycle begins anew [9]. As more clock gene transcription factors have been identified, sophisticated models of cycling transcriptional activation/repression have been developed, and account for many experimental observations [10]. Significantly, some clock genes, e.g. Period1/2, are immediate-early transcription factors, whose promoters also contain functional CREs (cAMP/Ca ${ }^{2+}$-response elements). In the $\mathrm{SCN}$, in vivo and in vitro, appropriate activation of cAMP/Ca ${ }^{2+}$ signalling by extracellular stimuli induces Period gene expression, and thereby facilitates clock resetting at night (phase entrainment) [11,12] (Figure 1).

\section{The plot thickens}

In attempts to reconcile genetic models with cellular data and circadian mutant mouse phenotypes, several difficulties are encountered. First, time-lapse imaging of rhythms in culture indicates that the accuracy and robustness of timekeeping in dissociated SCN neurons, and cultured fibroblasts, is poor compared with rhythms from intact SCN slices or whole animals (cycle-to-cycle period variation of $\sim 2 \%, 3 \%$ and $9 \%$ in mice, slices and isolated neurons respectively [13]). Secondly, whereas overexpression or homozygous deletion of 'essential' clock genes, e.g. Bmal1, Cryptochrome1\&2, often abolishes behavioural rhythms, PERIOD2::LUCIFERASE (PER2::LUC) rhythms in SCN slices are observed to persist $[14,15]$. This robustness to genetic lesion implies that SCN circuitry is competent to maintain CRE-mediated gene expression rhythms when rhythmic E-box activation is absent. In addition, pharmacological investigation of cellular timekeeping shows that, although rhythms are resilient to inhibition of global transcriptional rate [16], drugs that target assorted signalling systems elicit profound effects, e.g. inhibitors of casein kinase 1 increase intrinsic period, dose-dependently, from $\sim 24$ to $>30 \mathrm{~h}$ [17]. Moreover, in isolated human erythrocytes that lack DNA, nuclei and other organelles, 24-h rhythms in metabolism persist over several days in vitro [18].

Thus, although it is evident that contributions from transcriptional cycles to timekeeping are necessary for co-ordinated temporal organization of normal physiology and behaviour, and that circadian rhythms are cell-intrinsic, it is equally clear that transcription (cyclical or 
otherwise) is not required for cellular rhythms, and that detailed understanding of precise mammalian timekeeping requires deeper knowledge of mechanisms within the SCN.

\section{$\mathrm{SCN}$ again}

Our view of the SCN has evolved to become that of 'first among equals': a primary locus for co-ordinating rhythms throughout the rest of the body. Comprising 10000-20000 neurons, the SCN employs both humoral factors and axonal projections to other brain regions to facilitate maintenance of stable phase relationships between peripheral tissues [2]. Sited above the optic chiasm, a proportion of SCN neurons have excitatory glutamatergic innervations from the retinohypothalamic tract, receiving photic cues from both image- and non-image-forming photoreceptor cells, as well as non-photic signals from the brainstem, e.g. 5-hydroxytryptamine (serotonin) [19,20]. Concomitant with biological function, the SCN is therefore a hetergeneous assemblage of cells that integrates multiple inputs into the extant phase of oscillation, and in turn populates a diversity of output pathways to convey temporal cues appropriate to each target site. This complex cellular heterogeneity and circuit structure enables additional systems-level functionality, such as encoding daylength, to emerge [21,22]

\section{SCN neurophysiology}

Whereas circadian rhythms are ubiquitous in mammalian cells, the SCN exhibits much greater amplitude, robustness and accuracy resulting in, and from, increased interneuronal synchrony, i.e. amplitude and synchrony are mutually interdependent [23,24].

SCN electrophysiology is overtly rhythmic, with most neurons being depolarized ( 50 $\mathrm{mV}$ ) and firing APs (action potentials) during the day, but hyperpolarized $(\sim-60 \mathrm{mV})$ and silent at night [25]. Blockade of neurotransmission [e.g. with TTX (tetrodotoxin)] abolishes electrical rhythms, and induces rapid damping of amplitude with progressive interneuronal desynchronization [26]. By implication, electrical excitability is required for coupling between individual cellular oscillators, making the whole greater than the sum of its parts.

The axons of most SCN neurons project outwards to communicate with surrounding brain regions. Intra-SCN communication originates predominantly from exocytosis of dense-core vesicles, principally from dendritic sites [27]. Vesicle release is mostly non-synaptic or parasynaptic, is $\mathrm{Ca}^{2+}$-dependent and may involve retrograde transmission facilitated by neural back-propagation [28] and follow slower kinetics than for most excitable cells.

Metabotropic neuropeptide signalling appears to be essential to SCN timekeeping. Although functional electrical synapses exist, they are not required for timekeeping [29]. Similarly, no ionotropic neurotransmitter receptor has been demonstrated to be indispensable for SCN intrinsic timekeeping in vitro. For example, although intra-SCN synapses are mainly GABAergic, with most neurons synthesizing/releasing GABA ( $\gamma$-aminobutyric acid) and expressing $\mathrm{GABA}_{\mathrm{A}}$ receptors, chronic inhibition with bicuculline does not significantly affect timing [28,30]. GABA signalling does contribute to entrainment [31] and modulate amplitude, however, possibly by restricting the extent of resting membrane depolarization during the day, while hyperpolarizing it at night [30], possibly acting in concert with a nightly BK channel $\mathrm{K}^{+}$efflux [22].

Several neuropeptides mediate SCN interneuronal communication, the foremost being VIP (vasoactive intestinal peptide) which binds to VPAC2 (VIP receptor 2), primarily signalling through AC (adenylate cyclase) via $\mathrm{G}_{\mathrm{s} a}$ [32]. Auxiliary roles exist for GRP (gastrinreleasing peptide) and AVP (arginine vasopressin), both also signalling through their respective G-protein-coupled receptors to activate PLC (phospholipase C) [33]. VIP, GRP 
and AVP are expressed differentially in subpopulations throughout the SCN, although their receptors (particularly VPAC2) are more widely distributed [2]. Most likely, neuropeptide release occurs during the day in response to increased electrical activity facilitating vesicular exocytosis, this allows localized paracrine communication within the SCN network [15].

Mice with homozygous deletion of genes encoding VIP or VPAC2 exhibit severely disrupted behavioural rhythms. The resting membrane potential in SCN neurons from these knockout mice (in vitro) is hyperpolarized, exhibiting reduced electrical activity, compared with wild-type [34,35]. In SCN slices from homozygous VIP- or VPAC2-null mice, rhythms were profoundly affected. Most notably, the number of bioluminescent neurons was hugely reduced relative to wild-type, and rhythms in those neurons were stochastic, low-amplitude and desynchronized from each other, similar to dissociated neurons or fibroblasts. Critically, several cycles of higher-amplitude synchronized rhythms were rescued in VIP-null SCNs by exogenous VIP [34]. Similar observations were made in VPAC2-null slices, treated with forskolin to directly activate AC. Rhythmic amplitude was similarly rescued by GRP application, or by elevated intracellular $\mathrm{Ca}^{2+}\left\{\right.$ high $\left[\mathrm{K}^{+}\right]_{\mathrm{EC}}$ (extracellular $\mathrm{K}^{+}$concentration) $\}$ [35]. This implies that the timekeeping deficit in these mutant SCNs can be ascribed to deficits in $\mathrm{cAMP} / \mathrm{Ca}^{2+}$ signalling.

\section{Circadian second messenger signalling}

Second messenger signalling has long been viewed as an important means of cellular entrainment, e.g. in vitro, glutamate elicits $\mathrm{Ca}^{2+}$-mediated phase shifts in SCN, as does VIP acting via VPAC2/G $\mathrm{G}_{\mathrm{s} a} / \mathrm{AC} / \mathrm{cAMP}[3,19,32]$. Moreover, circadian modulation of second messenger signalling has been reported as a rhythmic cellular output, e.g. in the SCN, both in vivo and in vitro, $[\mathrm{cAMP}]_{\text {cyto }}$ (cytoplasmic cAMP concentration) varies $\sim$-fold, peaking shortly after projected dawn ( CT2 [36,37]). Similarly, fluorescent probes reveal SCN $\left[\mathrm{Ca}^{2+}\right]_{\text {cyto }}$ to be robustly rhythmic, again peaking shortly after projected dawn ( CT2 [38]). It is significant that rhythms in both $\left[\mathrm{Ca}^{2+}\right]$ and resting membrane potential are unaffected by TTX treatment [25]. Intriguingly, the morning peaks and nightly nadirs in cytosolic cAMP and $\mathrm{Ca}^{2+}$ are coincident, with maximal activity occurring in advance of the peak in electrical activity ( CT6, midday) and so cannot be driven by it [38]. Conversely, cAMP and $\mathrm{Ca}^{2+}$ are required for SCN electrophysiological excitability [39,40]. Signal transduction pathways have been established between elevated $\mathrm{cAMP} / \mathrm{Ca}^{2+}$ and transcriptional activation via CREs, e.g. in the Period1/2 promoter, so, logically, if second messenger signalling is both rhythmic output from, as well as input into, some hypothetical core clock mechanism, then dynamic cAMP/Ca ${ }^{2+}$ signalling becomes indistinguishable from that core mechanism [24]. Therefore appropriate manipulation of cAMP and/or $\mathrm{Ca}^{2+}$ signalling should determine the key properties of cellular rhythms, i.e. amplitude, phase and period.

\section{Amplitude}

CAMP_Treatments that chronically elevate [forskolin/IBMX (isobutylmethylxanthine)] or reduce (MDL12,330A, pertussis toxin) [cAMP $]_{\text {cyto }}$ induce dose-dependent damping of SCN rhythms and progressive interneuronal desynchronization, similar to VIP- or VPAC2-null SCNs. Normal rhythms return gradually following washoff $[30,37]$.

$\mathrm{Ca}^{2+}$-Treatments that chronically elevate (ryanodine, high $\left[\mathrm{K}^{+}\right]_{\mathrm{EC}}$ ) or inhibit $\left\{\mathrm{Ca}^{2+}\right.$ chelators, low $\left[\mathrm{Ca}^{2+}\right]_{\mathrm{EC}}$ (extracellular $\mathrm{Ca}^{2+}$ concentration), $\mathrm{Ca}^{2+}$-channel inhibitor cocktails \} dose-dependently reduce amplitude, with presumed desynchronization $[35,38,40,41]$.

Chronically elevated/reduced cytosolic cAMP/Ca ${ }^{2+}$ levels also increase/decrease PER2::LUC magnitude respectively, stressing the critical contribution that CRE activation 
makes to clock gene regulation. Such manipulations reveal the dependence upon dynamic second messenger-mediated interneuronal coupling for the reciprocal interaction between amplitude and synchrony inherent to SCN timekeeping [23].

Phase

cAMP-Following washoff of forskolin/IBMX-treated, but not vehicle-treated, SCN slices, regardless of the previous phase, the new phase of drug-treated slices is reset to dusk $(\sim \mathrm{CT} 12)$, when $[\mathrm{cAMP}]_{\text {cyto }}$ normally approaches its nadir, during the peak of PER2::LUC activity [37].

$\mathrm{Ca}^{2+}$-Glutamate-induced $\mathrm{Ca}^{2+}$-mediated phase-resetting of SCNs has been reported extensively, being mimicked by glutamate receptor agonists and blocked by antagonists [42]. $\mathrm{Ca}^{2+}$ influx also resynchronizes neurons in VPAC2-null SCNs, and release of SCN slices from medium with $0 \mathrm{mM} \mathrm{KCl}$ (low $\left[\mathrm{Ca}^{2+}\right]_{\text {cyto }}$ ) resets internal phase to just after dawn ( CT3) when the cytosolic $\mathrm{Ca}^{2+}$ peak is normally observed [35,41].

Thus pharmacologically enforced cAMP/Ca ${ }^{2+}$ transitions override prior phase, forcing SCN phase to whenever such transitions would normally occur within the self-sustained circadian cycle.

\section{Period}

CAMP—Non-competitive (p-site) inhibitors of AC dose-dependently, and reversibly, increase circadian period (to $>31 \mathrm{~h}$ ) in every tissue tested in vitro, and are additive to manipulations that increase SCN period by other mechanisms [37]. Increased mouse behavioural period in vivo was also observed when p-site inhibitor [THFA (tetrahydrofuryl alcohol)] was delivered continuously and directly to the SCNs via osmotic minipump [37].

$\mathrm{Ca}^{2+}$ - Although equivalent SCN experiments have yet to be performed, the period of rat

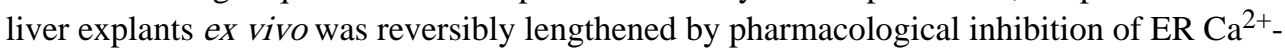
store release and import, as well as by membrane-permeant $\mathrm{Ca}^{2+}$ chelators [43]. Similar results may be expected using SCN slices.

\section{Clock timing and cross-talk}

Manipulation of SCN cAMP/Ca ${ }^{2+}$ signalling generally results in more marked SCN phenotypes than mutation/knockout of identified clock genes. Therefore, in addition to their other myriad biological roles [24], dynamic cAMP/Ca ${ }^{2+}$ signalling critically contributes to SCN timekeeping, raising the question: which signalling proteins are involved, and how might cross-talk with circadian transcriptional elements be achieved?

Wild-type SCN slices exhibit daily cycles of tandemly elevated cAMP and $\mathrm{Ca}^{2+}$, culminating in rhythmic CRE activation at Period gene promoters, acting synergistically with rhythmic E-box activation and thereby presumably amplifying the oscillation. Within the CREB [CRE-binding protein] transcription factors, ATF4 (activating transcription factor 4) has recently been implicated as one such terminal effector [44]. The SCN-specific pathways that facilitate CRE activation are ill-defined, but cAMP transduction certainly involves Epac (exchange protein directly activated by cAMP) with an auxiliary role for PKA (protein kinase A) [37]. For $\mathrm{Ca}^{2+}$, the effectors CaMKII $\left(\mathrm{Ca}^{2+} /\right.$ calmodulin-dependent protein kinase II), MAPK (mitogen-activated protein kinase) and PKC (protein kinase C) have been similarly implicated $[2,45]$. 
It is unknown whether any $\mathrm{AC}$ isoforms preferentially participate in cellular rhythms; however, the daily increase in SCN cytoplasmic $\mathrm{Ca}^{2+}$ signalling probably is initiated primarily from intracellular stores. Whereas $\operatorname{IP}_{3} \operatorname{Rs}\left[\operatorname{Ins}(1,4,5) P_{3}\right.$ receptors] and RyRs (ryanodine receptors) are certainly involved, the relative contributions made by different $\mathrm{Ca}^{2+}$-mobilizing messengers [Ins $(1,4,5) P_{3}$, cADPR (cADP-ribose), NAADP (nicotinic acid-adenine dinucleotide phosphate)] and $\mathrm{Ca}^{2+}$-induced $\mathrm{Ca}^{2+}$ release remain poorly characterized. Although plasma membrane $\mathrm{Ca}^{2+}$ flux is required for $\mathrm{SCN}$ timekeeping, this is probably an indirect consequence of the requirement for extracellular $\mathrm{Ca}^{2+}$ in vesicular exo/endo-cytotosis [46], and for replenishing depleted intracellular stores during SOCE (store-operated $\mathrm{Ca}^{2+}$ entry) [47]. Direct cross-talk between intracellular messengers systems, e.g. cAMP modulation of $\mathrm{IP}_{3} \mathrm{R}$ activity [46], have not been investigated in the SCN.

The transcriptional clock circuitry within the SCN modulates cAMP/Ca ${ }^{2+}$ signalling by several means. For example, gene expression rhythms are observed for several SCN neuropeptides, neuropeptide receptors and AC/RyR isoforms, and functional contributions to timekeeping have been established, i.e. factors which enable rhythmic transcription (input) are themselves rhythmically expressed (output) [2]. Furthermore, daytime repression of $\mathrm{G}_{\mathrm{i} / \mathrm{o}}$ has been reported, through rhythmic expression of RGS16 (regulator of G-protein signalling 16) [36]. Most significantly, CRYPTOCHROME1 was recently reported to directly inhibit $\mathrm{G}_{\mathrm{s} a}$ activity in vitro and in mouse liver in vivo [48]; if this mechanism operates in the SCN, then it may well contribute to the decline of $\mathrm{cAMP} / \mathrm{Ca}^{2+}$ late in the day, when CRYPTOCHROME levels are increasing.

\section{Paracrine positive-feedback coupling in the SCN}

Elevated cytosolic cAMP and $\mathrm{Ca}^{2+}$ are competent to activate plasma membrane cation channels, e.g. cAMP regulates $\mathrm{CNG}$ (cyclic-nucleotide-gated) channels to conduct mixed cation influx [49]; SOCE induces $\mathrm{Ca}^{2+}$ and mixed cation influx via Orai and TRPC (transient receptor potential canonical) channels, respectively [50]. Critically, persistent subthreshold cation channels exhibiting some properties similar to those of CNG/TRPC channels are observed in SCN slices [51]. It therefore seems plausible that shortly after (projected) dawn, prior timekeeping mechanisms facilitate elevated cytosolic cAMP/Ca ${ }^{2+}$ signalling. This increases the 'open' probability of cAMP/Ca ${ }^{2+}$-sensitive cation channels, thereby depolarizing the resting membrane potential (by $\sim 10 \mathrm{mV}$ ) and increasing AP firing probability. AP firing increases neuropeptide release, and neuropeptides act locally to stimulate further $\mathrm{cAMP} / \mathrm{Ca}^{2+}$ signalling in neighbouring neurons, which respond similarly. Clearly, this leads to positive feedback and sustained auto-amplification of cAMP/Ca ${ }^{2+}$ signalling within the SCN network, amplifying PERIOD1/2 expression in the process, in the same phase with E-box activation. It is presumed that this sustained second messenger activity is relaxed by some combination of vesicular neuropeptide depletion, receptor desensitization/internalization and clock-driven modulation of the $\mathrm{G}_{\mathrm{s}} / \mathrm{G}_{\mathrm{q}} / \mathrm{G}_{\mathrm{i} / \mathrm{o}}$ transduction pathways, e.g. by CRYPTOCHROME1 and RGS16. Some redundancy must exist between $\mathrm{Ca}^{2+}$ and cAMP signalling for timekeeping within individual neurons, but $\mathrm{SCN}$-intrinsic encoding of projected dawn surely relies upon the coincident detection of both second messenger systems being more active within the SCN network as a whole (Figure 2).

\section{Concluding remarks}

Initiated by cell-intrinsic mechanisms, neuropeptide-mediated paracrine positive feedback between the extensively coupled neurons within the SCN facilitates a sustained increase in cAMP/Ca ${ }^{2+}$ signalling during the day. This accounts for the enhanced amplitude, robustness and precision of the SCN compared with other tissues. Accordingly, SCN amplitude will be reinforced further when retinorecipient neurons receive photic inputs that evoke appropriate 
$\mathrm{Ca}^{2+}$ transients during the day. In contrast, when those same transients occur at night, recipient neurons will phase-shift relative to non-recipient neurons, resulting in an increased phase distribution across the SCN. Owing to SCN paracrine positive-feedback coupling, however, this transitory phase dispersal is integrated to become more coherent during the following day, resulting in a modest phase shift by the network as a whole.

Thus, whereas the basic mechanisms by which cells keep time remains unclear, the reason the SCN does it better has become increasingly transparent.

\section{Acknowledgments}

We thank G. Churchill, E. Herzog, D. Welsh, C. Allen and M. Hastings for their helpful discussion and suggestions.

Funding

J.S.O'N. and A.B.R. are supported by The Wellcome Trust [grant numbers 083643/Z/07/Z and 093734/Z/10/Z].

\section{Abbreviations used}

AC

AP

ATF4

AVP

$[\mathrm{cAMP}]_{\text {cyto }}$

CCG

CNG

CRE

CREB

CT

GABA

GRP

IBMX

$\mathbf{I P}_{\mathbf{3}} \mathbf{R}$

$\left[\mathrm{K}^{+}\right]_{\mathbf{E C}}$

RGS16

RyR

SCN

SOCE

TRPC

TTX

VIP

VPAC2 adenylate cyclase

action potential

activating transcription factor 4

arginine vasopressin

cytoplasmic cAMP concentration

clock-controlled gene

cyclic-nucleotide-gated

cAMP/Ca ${ }^{2+}$-response element

CRE-binding protein

circadian time

$\gamma$-aminobutyric acid

gastrin-releasing peptide

isobutylmethylxanthine

$\operatorname{Ins}(1,4,5) P_{3}$ receptor

extracellular $\mathrm{K}^{+}$concentration

regulator of G-protein signalling 16

ryanodine receptor

suprachiasmatic nucleus

store-operated $\mathrm{Ca}^{2+}$ entry

transient receptor potential canonical

tetrodotoxin

vasoactive intestinal peptide

VIP receptor 2 


\section{References}

1. Reddy AB, O'Neill JS. Healthy clocks, healthy body, healthy mind. Trends Cell Biol. 2010; 20:3644. [PubMed: 19926479]

2. Welsh DK, Takahashi JS, Kay SA. Suprachiasmatic nucleus: cell autonomy and network properties. Annu. Rev. Physiol. 2010; 72:551-577. [PubMed: 20148688]

3. Welsh DK, Yoo SH, Liu AC, Takahashi JS, Kay SA. Bioluminescence imaging of individual fibroblasts reveals persistent, independently phased circadian rhythms of clock gene expression. Curr. Biol. 2004; 14:2289-2295. [PubMed: 15620658]

4. Yoo SH, Yamazaki S, Lowrey PL, Shimomura K, Ko CH, Buhr ED, Siepka SM, Hong HK, Oh WJ, Yoo OJ, et al. PERIOD2::LUCIFERASE real-time reporting of circadian dynamics reveals persistent circadian oscillations in mouse peripheral tissues. Proc. Natl. Acad. Sci. U.S.A. 2004; 101:5339-5346. [PubMed: 14963227]

5. Deery MJ, Maywood ES, Chesham JE, Sladek M, Karp NA, Green EW, Charles PD, Reddy AB, Kyriacou CP, Lilley KS, Hastings MH. Proteomic analysis reveals the role of synaptic vesicle cycling in sustaining the suprachiasmatic circadian clock. Curr. Biol. 2009; 19:2031-2036. [PubMed: 19913422]

6. Doherty CJ, Kay SA. Circadian control of global gene expression patterns. Annu. Rev. Genet. 2010; 44:419-444. [PubMed: 20809800]

7. Reddy AB, Karp NA, Maywood ES, Sage EA, Deery M, O’Neill JS, Wong GK, Chesham J, Odell M, Lilley KS, et al. Circadian orchestration of the hepatic proteome. Curr. Biol. 2006; 16:11071115. [PubMed: 16753565]

8. Yamaguchi S, Mitsui S, Miyake S, Yan L, Onishi H, Yagita K, Suzuki M, Shibata S, Kobayashi M, Okamura $\mathrm{H}$. The $5^{\prime}$ upstream region of mPer1 gene contains two promoters and is responsible for circadian oscillation. Curr. Biol. 2000; 10:873-876. [PubMed: 10899004]

9. Reppert SM, Weaver DR. Coordination of circadian timing in mammals. Nature. 2002; 418:935941. [PubMed: 12198538]

10. Ukai H, Ueda HR. Systems biology of mammalian circadian clocks. Annu. Rev. Physiol. 2010; 72:579-603. [PubMed: 20148689]

11. Obrietan K, Impey S, Smith D, Athos J, Storm DR. Circadian regulation of cAMP response element-mediated gene expression in the suprachiasmatic nuclei. J. Biol. Chem. 1999; 274:1774817756. [PubMed: 10364217]

12. Tischkau SA, Mitchell JW, Tyan SH, Buchanan GF, Gillette MU. $\mathrm{Ca}^{2+} / \mathrm{cAMP}$ response elementbinding protein (CREB)-dependent activation of Per1 is required for light-induced signaling in the suprachiasmatic nucleus circadian clock. J. Biol. Chem. 2003; 278:718-723. [PubMed: 12409294]

13. Herzog ED, Aton SJ, Numano R, Sakaki Y, Tei H. Temporal precision in the mammalian circadian system: a reliable clock from less reliable neurons. J. Biol. Rhythms. 2004; 19:35-46. [PubMed: 14964702]

14. Ko CH, Yamada YR, Welsh DK, Buhr ED, Liu AC, Zhang EE, Ralph MR, Kay SA, Forger DB, Takahashi JS. Emergence of noise-induced oscillations in the central circadian pacemaker. PLoS Biol. 2010; 8:e1000513. [PubMed: 20967239]

15. Maywood ES, Chesham JE, O’Brien JA, Hastings MH. A diversity of paracrine signals sustains molecular circadian cycling in suprachiasmatic nucleus circuits. Proc. Natl. Acad. Sci. U.S.A. 2011; 108:14306-14311. [PubMed: 21788520]

16. Dibner C, Sage D, Unser M, Bauer C, d'Eysmond T, Naef F, Schibler U. Circadian gene expression is resilient to large fluctuations in overall transcription rates. EMBO J. 2009; 28:123134. [PubMed: 19078963]

17. Meng QJ, Maywood ES, Bechtold DA, Lu WQ, Li J, Gibbs JE, Dupre SM, Chesham JE, Rajamohan F, Knafels J, et al. Entrainment of disrupted circadian behavior through inhibition of casein kinase 1 (CK1) enzymes. Proc. Natl. Acad. Sci. U.S.A. 2010; 107:15240-15245. [PubMed: 20696890]

18. O’Neill JS, Reddy AB. Circadian clocks in human red blood cells. Nature. 2011; 469:498-503. [PubMed: 21270888] 
19. Brown TM, Piggins HD. Electrophysiology of the suprachiasmatic circadian clock. Prog. Neurobiol. 2007; 82:229-255. [PubMed: 17646042]

20. Leak RK, Card JP, Moore RY. Suprachiasmatic pacemaker organization analyzed by viral transynaptic transport. Brain Res. 1999; 819:23-32. [PubMed: 10082857]

21. VanderLeest HT, Houben T, Michel S, Deboer T, Albus H, Vansteensel MJ, Block GD, Meijer JH. Seasonal encoding by the circadian pacemaker of the SCN. Curr. Biol. 2007; 17:468-473. [PubMed: 17320387]

22. Colwell CS. Linking neural activity and molecular oscillations in the SCN. Nat. Rev. Neurosci. 2011; 12:553-569. [PubMed: 21886186]

23. Abraham U, Granada AE, Westermark PO, Heine M, Kramer A, Herzel H. Coupling governs entrainment range of circadian clocks. Mol. Syst. Biol. 2010; 6:438. [PubMed: 21119632]

24. Hastings MH, Maywood ES, O’Neill JS. Cellular circadian pacemaking and the role of cytosolic rhythms. Curr. Biol. 2008; 18:R805-R815. [PubMed: 18786386]

25. Pennartz CM, de Jeu MT, Bos NP, Schaap J, Geurtsen AM. Diurnal modulation of pacemaker potentials and calcium current in the mammalian circadian clock. Nature. 2002; 416:286-290. [PubMed: 11875398]

26. Yamaguchi S, Isejima H, Matsuo T, Okura R, Yagita K, Kobayashi M, Okamura H. Synchronization of cellular clocks in the suprachiasmatic nucleus. Science. 2003; 302:1408-1412. [PubMed: 14631044]

27. Castel M, Morris J, Belenky M. Non-synaptic and dendritic exocytosis from dense-cored vesicles in the suprachiasmatic nucleus. NeuroReport. 1996; 7:543-547. [PubMed: 8730825]

28. Gompf HS, Irwin RP, Allen CN. Retrograde suppression of GABAergic currents in a subset of SCN neurons. Eur. J. Neurosci. 2006; 23:3209-3216. [PubMed: 16820011]

29. Long MA, Jutras MJ, Connors BW, Burwell RD. Electrical synapses coordinate activity in the suprachiasmatic nucleus. Nat. Neurosci. 2005; 8:61-66. [PubMed: 15580271]

30. Aton SJ, Huettner JE, Straume M, Herzog ED. GABA and $\mathrm{G}_{\mathrm{i} / \mathrm{o}}$ differentially control circadian rhythms and synchrony in clock neurons. Proc. Natl. Acad. Sci. U.S.A. 2006; 103:19188-19193. [PubMed: 17138670]

31. Ehlen JC, Paul KN. Regulation of light's action in the mammalian circadian clock: role of the extrasynaptic GABA A receptor. Am. J. Physiol. Regul. Integr. Comp. Physiol. 2009; 296:R1606R1612. [PubMed: 19244580]

32. An S, Irwin RP, Allen CN, Tsai C, Herzog ED. Vasoactive intestinal polypeptide requires parallel changes in adenylate cyclase and phospholipase $\mathrm{C}$ to entrain circadian rhythms to a predictable phase. J. Neurophysiol. 105:2289-2296. [PubMed: 21389307]

33. Gamble KL, Allen GC, Zhou T, McMahon DG. Gastrin-releasing peptide mediates light-like resetting of the suprachiasmatic nucleus circadian pacemaker through cAMP response elementbinding protein and Per1 activation. J. Neurosci. 2007; 27:12078-12087. [PubMed: 17978049]

34. Aton SJ, Colwell CS, Harmar AJ, Waschek J, Herzog ED. Vasoactive intestinal polypeptide mediates circadian rhythmicity and synchrony in mammalian clock neurons. Nat. Neurosci. 2005; 8:476-483. [PubMed: 15750589]

35. Maywood ES, Reddy AB, Wong GK, O’Neill JS, O’Brien JA, McMahon DG, Harmar AJ, Okamura H, Hastings MH. Synchronization and maintenance of timekeeping in suprachiasmatic circadian clock cells by neuropeptidergic signaling. Curr. Biol. 2006; 16:599-605. [PubMed: 16546085]

36. Doi M, Ishida A, Miyake A, Sato M, Komatsu R, Yamazaki F, Kimura I, Tsuchiya S, Kori H, Seo $\mathrm{K}$, et al. Circadian regulation of intracellular G-protein signalling mediates intercellular synchrony and rhythmicity in the suprachiasmatic nucleus. Nat. Commun. 2011; 2:327. [PubMed: 21610730]

37. O’Neill JS, Maywood ES, Chesham JE, Takahashi JS, Hastings MH. cAMP-dependent signaling as a core component of the mammalian circadian pacemaker. Science. 2008; 320:949-953. [PubMed: 18487196]

38. Ikeda M, Sugiyama T, Wallace CS, Gompf HS, Yoshioka T, Miyawaki A, Allen CN. Circadian dynamics of cytosolic and nuclear $\mathrm{Ca}^{2+}$ in single suprachiasmatic nucleus neurons. Neuron. 2003; 38:253-263. [PubMed: 12718859] 
39. Atkinson SE, Maywood ES, Chesham JE, Wozny C, Colwell CS, Hastings MH, Williams SR. Cyclic AMP signaling control of action potential firing rate and molecular circadian pacemaking in the suprachiasmatic nucleus. J. Biol. Rhythms. 2011; 26:210-220. [PubMed: 21628548]

40. Shibata S, Shiratsuchi A, Liou SY, Ueki S. The role of calcium ions in circadian rhythm of suprachiasmatic nucleus neuron activity in rat hypothalamic slices. Neurosci. Lett. 1984; 52:181184. [PubMed: 6098875]

41. Lundkvist GB, Kwak Y, Davis EK, Tei H, Block GD. A calcium flux is required for circadian rhythm generation in mammalian pacemaker neurons. J. Neurosci. 2005; 25:7682-7686. [PubMed: 16107654]

42. Kim DY, Choi HJ, Kim JS, Kim YS, Jeong DU, Shin HC, Kim MJ, Han HC, Hong SK, Kim YI. Voltage-gated calcium channels play crucial roles in the glutamate-induced phase shifts of the rat suprachiasmatic circadian clock. Eur. J. Neurosci. 2005; 21:1215-1222. [PubMed: 15813931]

43. Báez-Ruiz A, Díaz-Muñoz M. Chronic inhibition of endoplasmic reticulum calcium-release channels and calcium-ATPase lengthens the period of hepatic clock gene Per1. J. Circadian Rhythms. 2011; 9:6. [PubMed: 21740569]

44. Koyanagi S, Hamdan AM, Horiguchi M, Kusunose N, Okamoto A, Matsunaga N, Ohdo S. cAMP response element-mediated transcription by activating transcription factor-4 (ATF4) is essential for circadian expression of the Period2 gene. J. Biol. Chem. 2011; 286:32416-32423. [PubMed: 21768648]

45. Lee Y, Lee J, Kwon I, Nakajima Y, Ohmiya Y, Son GH, Lee KH, Kim K. Coactivation of the CLOCK-BMAL1 complex by CBP mediates resetting of the circadian clock. J. Cell Sci. 2010; 123:3547-3557. [PubMed: 20930143]

46. Schweizer FE, Ryan TA. The synaptic vesicle: cycle of exocytosis and endocytosis. Curr. Opin. Neurobiol. 2006; 16:298-304. [PubMed: 16707259]

47. Cohen JE, Fields RD. CaMKII inactivation by extracellular $\mathrm{Ca}^{2+}$ depletion in dorsal root ganglion neurons. Cell Calcium. 2006; 39:445-454. [PubMed: 16519936]

48. Zhang EE, Liu Y, Dentin R, Pongsawakul PY, Liu AC, Hirota T, Nusinow DA, Sun X, Landais S, Kodama Y, et al. Cryptochrome mediates circadian regulation of cAMP signaling and hepatic gluconeogenesis. Nat. Med. 2010; 16:1152-1156. [PubMed: 20852621]

49. Kaupp UB, Seifert R. Cyclic nucleotide-gated ion channels. Physiol. Rev. 2002; 82:769-824. [PubMed: 12087135]

50. Cheng KT, Liu X, Ong HL, Swaim W, Ambudkar IS. Local $\mathrm{Ca}^{2+}$ entry via Orai1 regulates plasma membrane recruitment of TRPC1 and controls cytosolic $\mathrm{Ca}^{2+}$ signals required for specific cell functions. PLoS Biol. 2011; 9:e1001025. [PubMed: 21408196]

51. Kononenko NI, Medina I, Dudek FE. Persistent subthreshold voltage-dependent cation single channels in suprachiasmatic nucleus neurons. Neuroscience. 2004; 129:85-92. [PubMed: 15489031] 


\section{Future challenges}

i. Are rhythms in $\mathrm{cAMP} / \mathrm{Ca}^{2+}$ signalling ubiquitous to mammalian cells, and simply with higher amplitude in the SCN, or specific to SCN timekeeping?

ii. What licenses the increased $\mathrm{cAMP} / \mathrm{Ca}^{2+}$ signalling after dawn, and can it be blocked by inhibition of gene expression?

iii. What specific spatiotemporal dynamic of $\mathrm{SCN}$ cAMP/Ca ${ }^{2+}$ signalling encodes timekeeping information: is it AM (amplitude-modulated) or FM (frequencymodulated); global, local or microdomain-dependent?

iv. What is the contribution of other intracellular messengers and the cross-talk between them? 


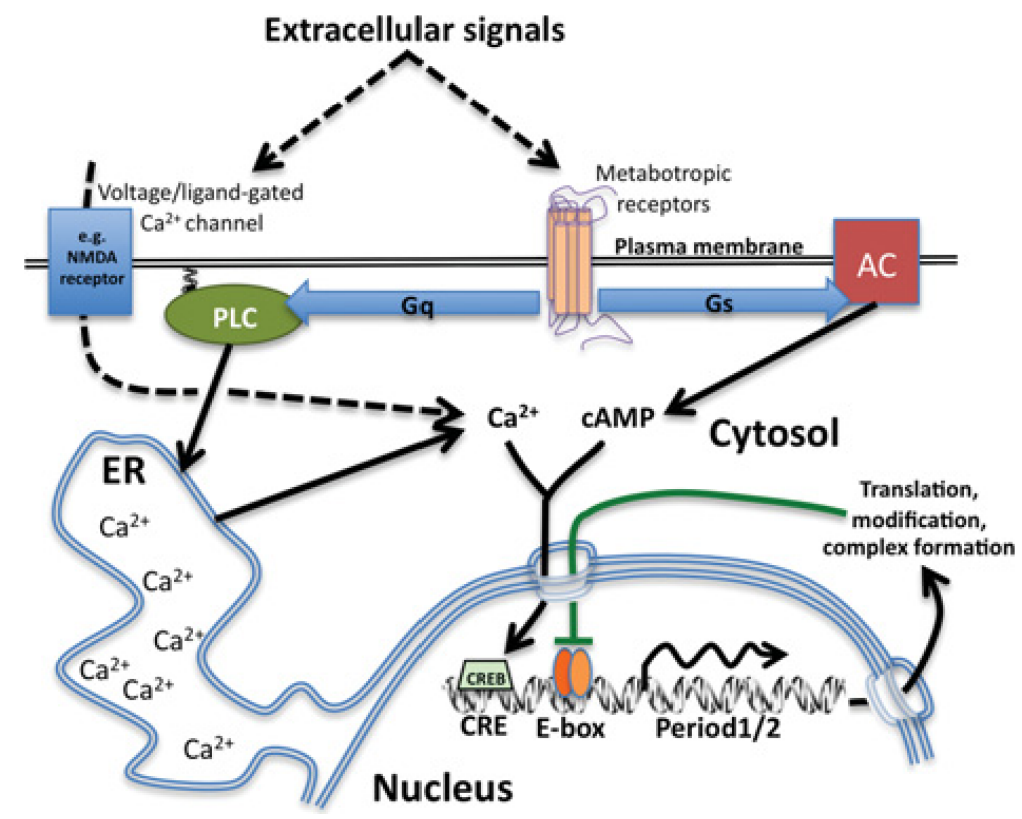

Figure 1. Schematic diagram of how rhythms in $\mathrm{SCN}$ neuronal 'clock gene' expression result from parallel activation at CRE and E-box promoter elements

Around projected dawn (black lines), increased cytosolic cAMP/Ca ${ }^{2+}$ signalling is driven by extracellular signals as well as cell-intrinsic mechanisms. This culminates in daily CREB activation acting in tandem with rhythmic transcriptional activation by CLOCK/BMAL1 (orange ovals). Around dusk, transcriptional repressor complexes (green line) inhibit CLOCK/BMAL1 activity at a time when $\mathrm{CAMP} / \mathrm{Ca}^{2+} / \mathrm{CREB}$ signalling would normally be reduced. At night, however, external cues, e.g. glutamate-induced $\mathrm{Ca}^{2+}$-influx (broken line) is sufficient to induce Period1/2 expression, thereby eliciting phase shifts. ER, endoplasmic reticulum; NMDA, $N$-methyl-D-aspartate; PLC, phospholipase C. 


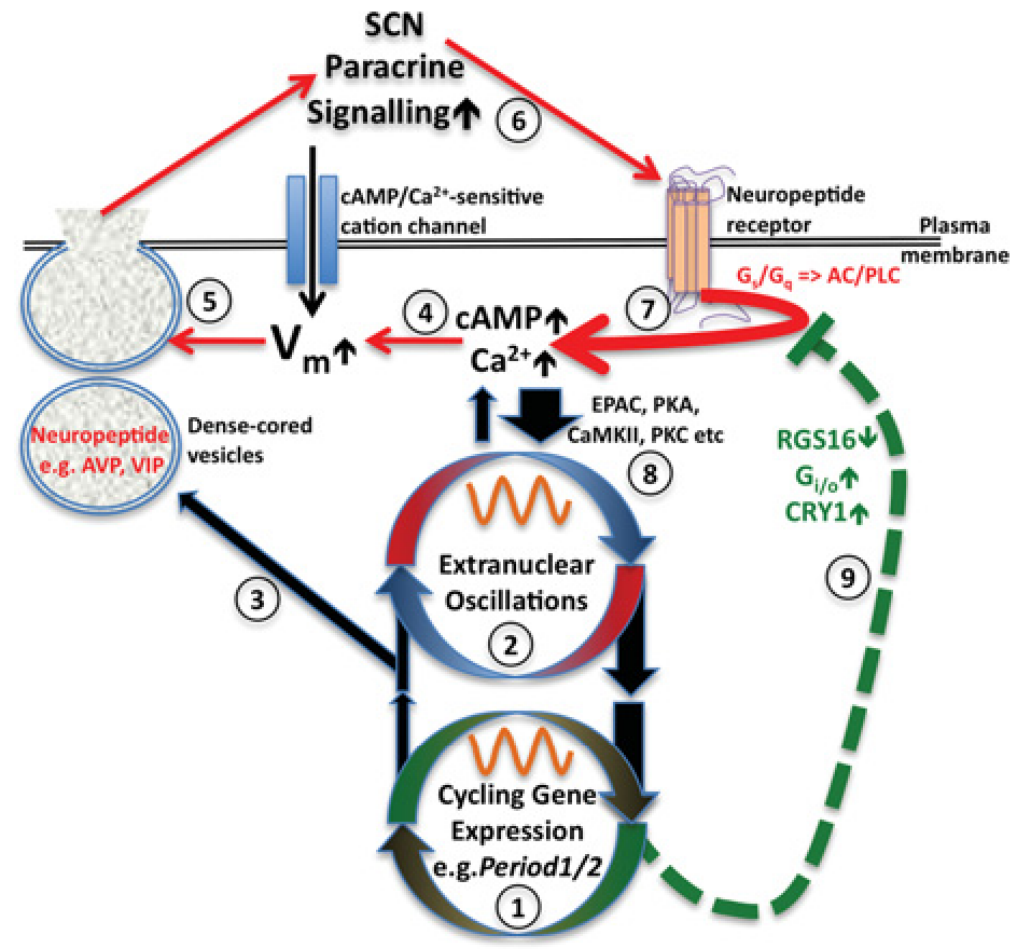

Figure 2. Schematic diagram of SCN paracrine positive-feedback coupling from a single neuron perspective

Cellular timekeeping results from reciprocal cross-talk between transcriptional-translational feedback loops (1) with extranuclear oscillations (2) in signalling and metabolism to facilitate rhythmic regulation of CCGs (3), e.g. AVP, and also increased cAMP/Ca ${ }^{2+}$ signalling around anticipated dawn (4). cAMP/Ca ${ }^{2+}$ depolarize resting membrane potential $\left(V_{\mathrm{m}}\right)$, thereby increasing electrical activity and neuropeptide release $(5)$, further elevating cAMP/Ca ${ }^{2+}$ signalling within the network, eliciting further neuropeptide release (6). Neuropeptide receptor activation amplifies cAMP/Ca ${ }^{2+}$ signalling (7), and activates downstream effectors (8). Later in the day, $\mathrm{cAMP} / \mathrm{Ca}^{2+}$ signalling decreases through neuropeptide depletion and/or receptor desensitization/internalization and/or change in gene expression of inhibitors of G-protein signalling (9). At night, cAMP/Ca ${ }^{2+}$-signalling, and therefore electrical activity, is reduced. $\mathrm{CaMKII}, \mathrm{Ca}^{2+} /$ calmodulin-dependent protein kinase II; EPAC, exchange protein directly activated by cAMP; PKA, protein kinase A; PKC, protein kinase C; PLC, phospholipase C. 